\title{
In vitro genotoxicity of piperacillin impurity-A
}

\author{
Magesh Vijayan $^{1^{\star}}$, M. Deecaraman ${ }^{1}$ and Kalaichelvan Thangavelu Pudupalayam ${ }^{2}$ \\ ${ }^{1}$ Department of Biotechnology, Dr. MGR Educational and Research Institute, N.H4, Periar E.V.R Road, Maduravoyal, \\ Chennai.-600095, Tamil Nadu, India. \\ ${ }^{2}$ University of Madras, CAS in Botany, Guindy Campus, Chennai - 600 025, Tamil Nadu, India.
}

Accepted 23 July, 2007

\begin{abstract}
The manufacturing and storage of the piperacillin produce different impurities of various concentrations, which may influence the efficacy and safety of the drug. Since no report of genotoxicity data is available on the impurities of piperacillin, further studies were designed and conducted to provide information for establishing the safety profile and qualification of the piperacillin impurity-A. Salmonella typhimurium strains were exposed to Piperacillin impurity-A for Ames tests. Neither increase in number of revertants indicative of mutagenic activity nor inhibition of bacterial growth, indicative of cytotoxicity were observed up to $5 \mathrm{mg} / \mathrm{plate}$ both in the presence and absence of metabolic activation. Similarly, chromosomal aberration assay did not reveal any significant alterations up to 5 $\mathrm{mg} / \mathrm{culture}$ as compared to the negative control both in the presence and absence of metabolic activation (S9 $\mathrm{mix}$ ). The results of these studies indicate that Piperacillin impurity-A is non-mutagenic in Ames test and non-clastogenic in chromosomal aberration study.
\end{abstract}

Key words: Piperacillin impurity-A, Salmonella typhimurium, mutagenic activity, Chromosomal aberration study.

\section{INTRODUCTION}

There is a growing concern about the role of impurities in drug substances. Safety regulations require insight into the structure and the amount of impurities present in the drug substance before they can be administered to humans. The presence of small amounts of impurities may influence the efficacy and safety of Piperacillin. The manufacturing and storage process produce impurities at various concentrations and occasionally, the concentration of these impurities crosses the threshold limit and warrants for establishing the safety profile $(\mathrm{ICH}$ Guideline, 2000a; Federal Register, 2000b).

Piperacillin an antibiotic of the penicillin group is widely used against a large number of gram-positive and gramnegative microorganisms (AHFS Drug Information, 2002). Various impurities of Piperacillin are reported in PHARMEUROPA (2002). However, no genotoxicity data is available on impurities. Piperacillin impurity-A is a prominent degradation product of Piperacillin that appears

\footnotetext{
*Corresponding author. E-mail: mahesharavind2006@yahoo.co.in. Tel: +919840343870.
}

during manufacturing and storage process. As the level of this impurity is comparatively higher and failed to pass the validation criteria of computer-assisted toxicity prediction carried out by "Topkat" software, the present genotoxic studies were designed and conducted to provide the information for establishing the safety profile and qualification of the impurity.

\section{MATERIALS AND METHODS}

Structure of piperacillin impurity-A

The structure of piperaciilin impurity-A given in Figure 1 was identified and characterized using LC- MS and NMR. The selected Piperacillin impurity-A was isolated with HPLC purity of $92.56 \%$ and molecular weight of 715.8 , with molecular formula $\mathrm{C}_{31} \mathrm{H}_{37} \mathrm{~N}_{7} \mathrm{O}_{9} \mathrm{~S}_{2}$ The chemical name of Piperacillin impurity-A is 6[6-[[2-[[(4-Ethyl2,3-dioxo-1-piperazine1-yl)carbonyl]amino]2phenylacetyl]amino]-

3,3-dimethyl-7-oxo-4-thia-1-azabicyclo heptanecarbonyl]amino]3,3-dimethyl-7-oxo-4-thia-1-azabicyclo [3.2.0] heptane-2-carboxylic acid. It was subjected to in vitro genotoxicity screening for the qualification of impurity as per the $\mathrm{ICH}$ recommendation (ANDAs impurities in drug products 1998; impurities in new substances in ANDAs, 2000). 


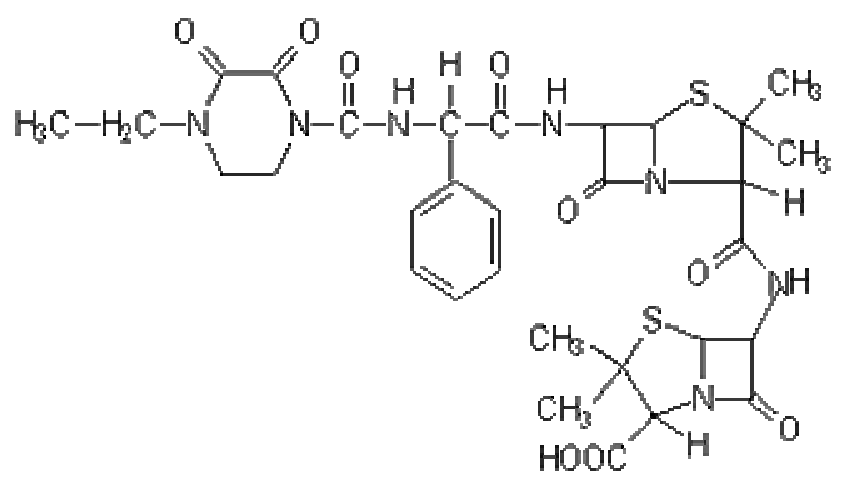

Figure 1. Structure of Piperacillin impurity-A.

\section{Chemicals}

Dimethyl sulfoxide (DMSO- CAS no. 67-68-5), nicotinamide adeninedinucleotide phosphate sodium salt (NADP-CAS no 214664-6), D-glucose-6-phosphate disodium salt (CAS no 3671-99-6), L-histidine monohydrate (CAS no 7048-02-4), d-biotin (CAS no 5885-5) were purchased from Sigma Chemical Company and Minimal Essential Medium (MEM CAT no 41090-036) procured from Gibco. Standard mutagens; 2-aminofluorene (CAS no 613-13-8), mitomycin C (CAS no 56-07-7), 4-nitroquinolene-1-Oxide (CAS no 56-57-5), sodium azide (CAS no 26628-22-8) and benzo(a)pyrene (CAS no 200-028-5) were also obtained from Sigma. Oxoid Nutrient Broth No. 2 (Oxoid) and Difco Bacto Agar (Difco) were used for the preparation of bacterial growth media.

\section{Ames assay}

Salmonella typhimurium strains TA97a, TA98, TA100, TA1535 and TA102 were obtained from Bruce Ames Laboratory, Molecular and Cell Biology, University of California, and checked for their viable counts and genotype characteristics. Plate incorporation method (Maron and Ames, 1983) using histidine-dependent strains of $S$. typhimurium TA 97a, TA 98, TA 100, TA 102 and TA 1535 in the presence and absence of metabolic activation system (S9 liver fraction) was adopted for assessing the mutagenicity.

Based on the results of cytotoxicity test, piperacllin impurity-A was tested for its mutagenic properties at five different concentrations viz., 5, 2.5, 1.25, and $0.625 \mathrm{mg} /$ plate. $100 \mu \mathrm{l}$ of various concentrations of impurity dissolved in dimethyl sulfoxide were added to $2 \mathrm{ml}$ top agar mixed with $100 \mu \mathrm{l}$ of bacterial culture and then poured on to a plate containing minimal glucose agar. These plates were incubated at $37^{\circ} \mathrm{C}$ for $48 \mathrm{~h}$ and his+ revertant colonies were manually counted and the results were shown as the mean of the three plates with standard deviation. The influence of metabolic activation was tested by adding $500 \mu \mathrm{l}$ of S9 mixture. The experiments were analysed in triplicate and was repeated again to confirm the result. The criteria employed to interpret the results of Ames test as positive were similar to those used in regulatory guidelines (OECD and ICH Guidelines). The number of induced mutation should be at least twice the activity observed in negative control and there must be a reproducible dose response curve. Concurrent positive and negative (dimethyl sulfoxide) controls were used in the study. The standard mutagens used as positive controls in each experiment were without metabolic activation, 4-nitroquinoline 1- Oxide (5 $\mu \mathrm{g} /$ plate) for strain TA 97a and TA98, Sodium azide (5 $\mu \mathrm{g} / \mathrm{plate})$ for strain TA 100 and TA 1535, Mitomycin-C (0.02 $\mathrm{mg} /$ plate) for TA 102. In case of positive controls with metabolic activation, 2-aminoflurene $(20 \mu \mathrm{g} /$ plate $)$ for TA97a, TA98,
TA100, TA 1535 and TA 102.

\section{Chromosomal aberration assay}

Chinese Hamster Ovary cell line obtained from National Centre for Cell Science, Pune were used for in vitro chromosomal aberration study. Monolayer cultures of $80 \%$ confluency were cultured at a cell density of $2.3 \times 10^{5}$ cells per culture and $24 \mathrm{~h}$ after culturing, the cells were exposed to the test substance with and without Aroclor 1254 - induced wistar rats S-9 (Venitt et al., 1990). As no precipitation and reduced mitotic index were recorded for impurity of piperacillin at $5 \mathrm{mg} /$ culture, dose levels of $5,2.5$ and 1.25 $\mathrm{mg} /$ culture were selected and exposed to cell cultures in duplicate (U.S. Environmental Protection Agency, 1998). Concurrent positive controls mitomycin- $C$ with out $S-9$ and benzo(A)pyrene with $S-9$ and negative control (DMSO) were used for the study. Cell cultures were incubated at $37^{\circ} \mathrm{C}$, harvested at $18 \mathrm{~h}$ after exposure and the cells were stained with $5 \%$ Giemsa. A total of about 200 metaphases were observed for structural chromosome aberrations, including both chromosomes and chromatids (that is, break, deletion, fragments and exchanges) were recorded. Gaps were recorded but not included in the aberration frequency.

\section{RESULTS AND DISCUSSION}

All the strains of $S$. typhimurium; TA 97a, TA 98, TA 100, TA 102 and TA 1535, exposed to different concentrations of Piperacillin impurity-A, did not show two fold or greater increase in the mean number of revertants as compared to negative control group given in Table 1. All strains used in the study exhibited marked increase ( $>10$ fold) in the number of revertants when treated with positive control agents. The results confirmed the sensitivity of the tester strains to mutagens and thus the validity of the assay. The results indicated that the mean number of histidine revertants in the treatment groups were comparable to the mean number of revertants in the negative control group in all the five $S$. typhimurium tester strains viz., TA 97a, TA 98, TA 100, TA 102 and TA 1535 both in the absence and presence of metabolic activation. The impurity of piperacillin up to $5 \mathrm{mg} /$ plate in the presence and absence of metabolic activation was found to be non-mutagenic to all the five $S$. typhimurium tester strains.

Similarly in vitro chromosomal aberration assay did not reveal any significant alterations up to $5 \mathrm{mg} / \mathrm{culture}$ given in Table 2 as compared to the negative control both in the presence and absence of metabolic activation (S9 mix) but the positive controls induced aberration. The chromosomal aberrations recorded per cell in the presence of metabolic activation was $0.01,0.00$ and 0.00 at $5,2.5$ and $1.25 \mathrm{mg}$ per culture respectively and 0.01 in vehicle control and 0.08 in the positive control group. The number of chromosomal aberrations per cell recorded in the absence of metabolic activation was $0.01,0.00$ and 0.00 at $5,2.5$ and $1.25 \mathrm{mg}$ per culture respectively, 0.01 in vehicle control and 0.08 in the positive control group. Piperacillin impurity-A up to $5 \mathrm{mg} / \mathrm{ml}$ is found to be nonclastogenic to Chinese Hamster Ovary cell lines both in the presence and absence of metabolic activation. 
Table 1. Mean plate count of mutagenicity study.

\begin{tabular}{|c|c|c|c|c|c|c|c|c|c|c|}
\hline \multirow{3}{*}{$\begin{array}{c}\text { Dose } \\
\text { Levels } \\
(\mu \mathrm{g} / \text { plate })\end{array}$} & \multicolumn{10}{|c|}{ Revertant colonies / Plate (Mean $9 \mathrm{n}=3$ ) \pm S. D.) } \\
\hline & \multicolumn{2}{|c|}{ TA 97a } & \multicolumn{2}{|c|}{ TA 98} & \multicolumn{2}{|c|}{ TA 1535} & \multicolumn{2}{|c|}{ TA 100} & \multicolumn{2}{|c|}{ TA 102} \\
\hline & - S9 & +S9 & -S9 & +S9 & -59 & +S9 & $-S 9$ & +S9 & -S9 & +S9 \\
\hline NC (DMSO) & $180 \pm 4$ & $175 \pm 6$ & $44 \pm 3$ & $49 \pm 7$ & $16 \pm 2$ & $17 \pm 3$ & $175 \pm 6$ & $177 \pm 10$ & $298 \pm 7$ & $300 \pm 9$ \\
\hline 5 & $180 \pm 7$ & $185 \pm 2$ & $39 \pm 3$ & $45 \pm 4$ & $15 \pm 5$ & $20 \pm 7$ & $174 \pm 10$ & $183 \pm 11$ & $302 \pm 7$ & $293 \pm 7$ \\
\hline 2.5 & $177 \pm 6$ & $192 \pm 3$ & $39 \pm 4$ & $44 \pm 6$ & $18 \pm 3$ & $19 \pm 2$ & $182 \pm 4$ & $183 \pm 10$ & $295 \pm 6$ & $304 \pm 7$ \\
\hline 1.25 & $178 \pm 7$ & $182 \pm 3$ & $44 \pm 3$ & $40 \pm 5$ & $18 \pm 3$ & $17 \pm 5$ & $185 \pm 6$ & $177 \pm 9$ & $300 \pm 10$ & $296 \pm 4$ \\
\hline 0.625 & $181 \pm 2$ & $182 \pm 3$ & $41 \pm 7$ & $44 \pm 4$ & $15 \pm 4$ & $20 \pm 2$ & $182 \pm 7$ & $185 \pm 5$ & $301 \pm 6$ & $303 \pm 4$ \\
\hline PC SA & NA & NA & NA & NA & $1228 \pm 45$ & NA & $2251 \pm 69$ & NA & NA & NA \\
\hline PC 4NQNO & $1891 \pm 15$ & NA & $842 \pm 53$ & NA & NA & NA & NA & NA & NA & NA \\
\hline PC MMC & NA & NA & NA & NA & NA & NA & NA & NA & $3435 \pm 63$ & NA \\
\hline PC 2AF & NA & $2202 \pm 16$ & NA & $1517 \pm 40$ & NA & $721 \pm 21$ & NA & $2719 \pm 28$ & NA & $3176 \pm 54$ \\
\hline
\end{tabular}

Key: $\mu \mathrm{g}=$ microgram, S.D. = Standard deviation, $\mathrm{NC}=$ Negative control, DMSO = Dimethyl sulfoxide PC = Positive control, $4 \mathrm{NQNO}=$ 4Nitroquinolene $\mathrm{N}$ Oxide, $\mathrm{SA}=$ Sodium azide, $\mathrm{MMC}=$ Mitomycin $\mathrm{C}, 2 \mathrm{AF}=2 \mathrm{Aminofluorene}, \mathrm{NA}=$ Not Applicable

Table 2. Summary of chromosomal aberration assay in $\mathrm{CHO}$ cell line.

\begin{tabular}{|c|c|c|c|c|c|c|c|c|c|}
\hline \multirow{3}{*}{$\begin{array}{l}\text { Dose (mg/ } \\
\text { culture) }\end{array}$} & \multirow{3}{*}{ S9 } & \multicolumn{8}{|c|}{ Break analysis } \\
\hline & & \multirow{2}{*}{$\begin{array}{l}\text { Total } \mathrm{N}^{\circ} \text { of } \\
\text { metaphases } \\
\text { analyzed }\end{array}$} & \multirow{2}{*}{ TotaL $\mathbf{N}^{\circ}$ of aberrations } & \multicolumn{3}{|c|}{ Type of aberrations } & \multirow{2}{*}{ Total cells with aberrations } & \multirow{2}{*}{ Aberrations/ cell } & \multirow{2}{*}{$\%$ Cells with aberratons } \\
\hline & & & & Gap & Chromatid & Chromosome & & & \\
\hline \multirow{2}{*}{$\begin{array}{c}\mathrm{NC} \\
(\mathrm{DMSO})\end{array}$} & - & 200 & 1 & 1 & 0 & 0 & 1 & 0.01 & 1 \\
\hline & + & 200 & 0 & 0 & 0 & 0 & 0 & 0.00 & 0 \\
\hline \multirow{2}{*}{5} & - & 200 & 1 & 1 & 0 & 0 & 1 & 0.01 & 1 \\
\hline & + & 200 & 0 & 0 & 0 & 0 & 0 & 0.00 & 0 \\
\hline \multirow{2}{*}{2.5} & - & 200 & 0 & 0 & 0 & 0 & 0 & 0.00 & 0 \\
\hline & + & 200 & 0 & 0 & 0 & 0 & 0 & 0.00 & 0 \\
\hline \multirow{2}{*}{1.25} & - & 200 & 0 & 0 & 0 & 0 & 0 & 0.00 & 0 \\
\hline & + & 200 & 0 & 0 & 0 & 0 & 0 & 0.00 & 0 \\
\hline $2.5 \mu \mathrm{g} / \mathrm{ml}(\mathrm{MIT})$ & - & 200 & 8 & 4 & 0 & 4 & 8 & $0.08^{*}$ & $8^{*}$ \\
\hline $0.03 \mu \mathrm{g} / \mathrm{ml}(\mathrm{BP})$ & + & 200 & 7 & 5 & 0 & 3 & 8 & $0.08^{*}$ & $8^{*}$ \\
\hline
\end{tabular}

$\mathrm{BP}=\operatorname{Benzo}(\mathrm{A})$ pyrene $(\mathrm{S9}+), \mathrm{NC}=$ Normal control, DMSO = Dimethyl sulfoxide, MIT = Mitomycin-C $(\mathrm{S} 9-), \mathrm{N}^{\circ}=$ number

${ }^{*}$ Significant at $95 \%$ confidence level $(p=0.05)$. 


\section{REFERENCE}

AHFS Drug Information (2002). Bethesda, MD: American Society of Health Systems Pharmasits.

ANDAs Impurities in Drug Products (1998). Guidance for Industry, Food and Drug Administration. U.S. Department of Health and Human Services, Center Drug Eval. Res. (CDER). pp. 1-14.

Impurities in Drug Substances...ANDAs (2000). Int. J. Gen. Drugs. 3(8): 365-379.

International Conference on Harmonisation (ICH) (2000a). Draft revised Guidance on Impurities in New Drug products. 65(139): 4479144797.

International Conference on Harmonisation (ICH) (2000b). Guidance on Q6A Specification: Test procedures and acceptance criteria for new drug substances and new drug products: Chemical Substance. Federal Register. 65(251): 83041- 61.
Maron DM, Ames BM (1983). Revised methods for the Salmonella mutagenicity test. Mutat. Res. $113: 173-215$.

OECD Guidelines for Testing of Chemicals (1987). Number 401. Pharmeuropa (2002). 14(3): 422-424.

U.S Environmental Protection Agency (1998). Health Effects Test Guidelines OPPTS 870.5375 EPA 712-C-98-223.

Venitt S, Crofton-Sleigh C, Forster R (1990). Assay for the Detection of Chemically -Induced Chromosome Damage in Cultured Mammalian Cells, In: Mutagenicity Testing - Practical Approach, Venitt S, Parry JM [eds], pp. 187-232. 